\section{Effect of Cold Acclimation and Freezing on Spring Dead Spot Severity in Bermudagrass}

F.B. Iriarte

Department of Plant Pathology, Kansas State University, 4024 Throckmorton Hall, Manhattan, KS 66506

\section{J.D. Fry}

Department of Horticulture, Forestry and Recreation Resources, Kansas State University, 2021 Throckmorton hall, Manhattan, KS 66506

\section{D.L Martin}

Department of Horticulture and Landscape Architecture, Oklahoma State University, Stillwater, OK 74078

T.C. Todd and N.A. Tisserat ${ }^{1}$

Department of Plant Pathology, Kansas State University, 4024 Throckmorton Hall, Manhattan, KS 66506

Additional index words. Ophiosphaerella korrae, Ophiosphaerella herpotricha, Ophiosphaerella. narmari, root infecting fungi, turfgrass

\begin{abstract}
Spring dead spot (SDS), caused by three root-infecting species of Ophiosphaerella, is a destructive disease of bermudagrass (Cynodon spp.L.C. Rich). We tested the effects of incubation temperature and duration, and exposure to decreasing freezing temperatures on bermudagrass shoot survival following inoculation with SDS pathogens. Inoculated plants exposed to freezing temperatures as high as $-2^{\circ} \mathrm{C}$ following a two month incubation exhibited extensive shoot mortality and had SDS symptoms consistent with those observed in the field. Lowering the freezing temperature from -2 to $-8{ }^{\circ} \mathrm{C}$ increased disease severity and shoot mortality on noninoculated bermudagrass. Inoculated bermudagrass incubated for 1 month in the greenhouse, then for an additional month at $4^{\circ} \mathrm{C}$ had greater shoot mortality following freezing than plants incubated at $25^{\circ} \mathrm{C}$. Although cold acclimation and freezing intensified SDS symptoms, the technique did not reliably distinguish between resistant and susceptible cultivars.
\end{abstract}

Spring dead spot, caused by the three closely related soil-borne fungi Ophiosphaerella korrae (J. Walker \& A. M. Smith) Shoemaker \& C. E. Babcock, O. narmari (J. Walker \& A. M. Smith) Wetzel, Hulbert \& Tisserat, and $O$. herpotricha (Fr.: Fr.) J. Walker, is a disease of common bermudagrass (Cynodon dactylon(L.) Pers.) and its hybrids (C. dactyon x C. transvaalensis Burtt-Davy) in the United States (Crahay, et al., 1988; Endo et al. 1985; Tisserat et al., 1989; Wetzel et al., 1999) and Australia (Hawkes, 1987; Smith, 1971). SDS results in the formation of circular dead spots in spring as the turfgrass breaks winter dormancy. These spots are usually less than $1 \mathrm{~m}$ in diameter, but they may coalesce to blight larger areas of turfgrass. Roots and stolons within patches are severely rotted and bermudagrass recovery during the summer is slow. Dead spots may reappear in the same location each year.

Control of SDS has been difficult to achieve by cultural or chemical practices. Reducing thatch by aerification and vertical mowing, using ammonium-based fertilizers or sulfur to reduce soil $\mathrm{pH}$, and increasing potassium levels in the soil, have provided only moderate reductions in SDS severity (Dernoeden et al., 1991; Tisserat and Fry, 1997). Similarly, preventive fungicide applications in fall or spring generally have not

Received for publication 27 May 2004. Accepted for publication 21 Sept. 2004. We thank the United State Golf Course Association and the Kansas Turfgrass Foundation for support.

${ }^{1}$ Current address: Bioagricultural Sciences and Pest Management, Colorado State University, Ft. Collins, 80527; e-mail Ned.Tisserat@colostate.edu. provided consistent control of SDS (Tisserat and Fry, 1997)

Another method of managing SDS is the use of moderately resistant cultivars. Pair et al. (1986) observed that the bermudagrass hybrid 'Midiron' exhibited increased winter hardiother common bermudagrass selections and to 'Tifway' hybrid bermudagrass. This observation was corroborated by others (Tisserat et al., 1989; Baird et al., 1998) in subsequent field trials. Several other vegetative and seeded bermudagrass cultivars with improved turf quality, cold tolerance and increased resistance to SDS have been identified (Baird et al., 1998; Martin et al., 2001a, 2001b).

Current techniques for screening new bermudagrass selections for resistance to SDS are slow and relatively labor intensive. Typically, SDS symptoms do not develop with consistency until 2 years after field inoculation (Baird et al., 1998; Tisserat et al., 1989). This requires that a relatively large number of bermudagrass selections must be managed in the field for 3 or more years to assess accurately SDS resistance. Early attempts to develop a more rapid greenhousebased screening procedure for SDS involved inoculating plants, incubating them for several months and then rating roots for discoloration and rotting (Baird et al., 1998; Tisserat et al., 1989).All selections exhibited root discoloration but none developed shoot mortality typical of SDS and no differences among selections were detected. Nus and Shashikumar (1993) found that inoculation of bermudagrass cultivars with ness and less SDS severity when compared to
O. korrae increased the temperature at which freeze injury to roots occurred, and that the effect was more pronounced on the susceptible cultivar. Thus, exposure to freezing temperatures following fungal infection of roots might be a useful technique for screening bermudagrass selections for SDS resistance.

The objective of our research was to develop techniques for consistently reproducing SDS symptoms on bermudagrass in a controlled environment. Specifically, we tested the effects of incubation temperature and duration, and exposure to decreasing freezing temperatures on bermudagrass shoot survival following inoculation with SDS pathogens.

\section{Materials and Methods}

Incubation duration. An experiment was conducted to determine the effect of two inoculum levels of four Ophiosphaerella isolates, and the duration of incubation at $4{ }^{\circ} \mathrm{C}$, on shoot survival of 'Midlawn' and 'Tifgreen' bermudagrasses. Soil-free stolons of each cultivar were placed in $6.4 \times 6.4$-cm plastic pots containing a steamed 1 soil : 1 perlite $: 1$ peat mixture (by volume) and plants were grown in the greenhouse for 4 months. Plants were watered, fertilized, and trimmed with scissors as needed. Soil in four pots of each cultivar was amended with two or four sterilized oats or oats infested with $O$. herpotricha isolate KS-1, O. narmari isolate $\mathrm{KS} 370, O$. korrae isolate A16-C4 representing an amplified fragment length polymorphism group (AFLP group I) widely distributed on kentucky bluegrass and bermudagrass in the northern United States (Iriarte, 2003; Wetzel et al. 1999), or O. korrae isolate MS-73 representing an AFLP group (group II) distributed in the southern United States (Wetzel et al. 1999). Infested oat seeds, prepared as previously described (Tisserat et al., 1989), were inserted into the potting mix about $2 \mathrm{~cm}$ below the surface and $0.5 \mathrm{~cm}$ deep into the side of the root-soil plug. The grass was then repotted. The process was repeated on four additional pots of each cultivar after 15 and 30 d. All pots were placed in the greenhouse at 21 to $28{ }^{\circ} \mathrm{C}$ for 1 month as previously described, then moved to a growth chamber at a constant $4{ }^{\circ} \mathrm{C}$ with a 12-h photoperiod (light intensity $\left.200 \mu \mathrm{mol} \mathrm{m}{ }^{-2} \cdot \mathrm{s}^{-1}\right)$. The staggered inoculation dates resulted in the three sets of plants being incubated at $4{ }^{\circ} \mathrm{C}$ for 15,30 , or $45 \mathrm{~d}$. All plants were then placed in a programmable freezer (Tenney Engineering, Union, N.J.) at $0{ }^{\circ} \mathrm{C}$. Ice was placed on top of the plants to speed the cooling process to $0{ }^{\circ} \mathrm{C}$. Soil temperature at a depth of $1.5 \mathrm{~cm}$ was measured with a thermocouple embedded in a pot located in the center of the chamber. The chamber temperature was lowered by $1{ }^{\circ} \mathrm{C} \cdot \mathrm{h}^{-1}$ until the soil temperature reached and was maintained at $-4{ }^{\circ} \mathrm{C}$ for $1 \mathrm{~h}$. Pots then were held at $4{ }^{\circ} \mathrm{C}$ for $24 \mathrm{~h}$ to allow the soil to thaw slowly. Bermudagrass leaves in all pots were killed following freezing and it was not possible to immediately assess treatment effects on shoot mortality. Therefore, pots were placed in the greenhouse for 1 month at temperatures ranging from 21 to $28^{\circ} \mathrm{C}$ to allow for bermudagrass regrowth. Percentage shoot 

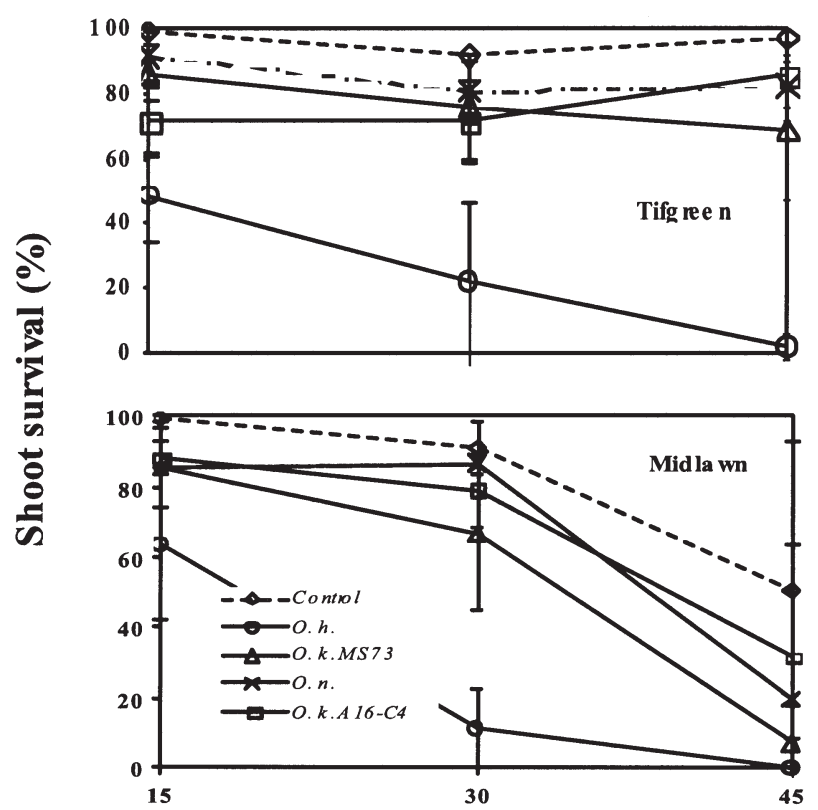

Incubation at $4^{\circ} \mathrm{C}$ (days)
Fig. 1. Shoot survival in two bermu-

survival was determined by dividing the number of live shoots by the total number of shoots in each pot. Data for each cultivar were analyzed separately as a 2 (inoculum level) $\times 3$ (incubation period) $\times 5$ (pathogen) factorial design with 4 replications using SAS (version 8.11 for Windows; SAS Institute, Cary, N.C.).

Cold acclimation and freezing. Bermudagrass cultivars 'Tifgreen', 'Champion', 'Midlawn' and 'Guymon' were grown as previously described. Four sterile oats or oats infested with a mixture of three O. korrae isolates (A16-C4, A11-84A, and A16-3-2) representing AFLP group I, three O. korrae isolates (AR155, MS73, and AL-3876) representing an AFLP group II or a single isolate of $O$. herpotricha (KS-1) were inserted into the potting mix as previously described. Inoculated plants were placed in the greenhouse at 21 to 28 ${ }^{\circ} \mathrm{C}$ for 1 month. Eight pots of each treatment combination (cultivar $x$ inoculant) were then placed in growth chambers at a constant $25{ }^{\circ} \mathrm{C}$ (nonacclimated) or $4{ }^{\circ} \mathrm{C}$ (cold-acclimated). After 1 month, cold-acclimated plants were placed in the freezing chamber at $0{ }^{\circ} \mathrm{C}$, and the temperature was lowered $1^{\circ} \mathrm{C} \cdot \mathrm{h}^{-1}$ as previously described. Two pots of each cultivar $\times$ SDS pathogen combination were removed when soil temperatures reached $-2,-4,-6$, or $-8^{\circ} \mathrm{C}$. The same procedure was followed the next day for the nonacclimated plants. Percentage shoot survival

Fig. 2. Shoot survival in four bermudagrass cultivars after inoculation with $O$ herpotricha and $O$. korrae (isolates representing AFLP groups I and II). Plants were incubated in the greenhouse for 1 month and then in a growth chamber at $25{ }^{\circ} \mathrm{C}$ for an additional month before freezing at either $-2,-4,-6$, or $-8{ }^{\circ} \mathrm{C}$. Vertical bars represent $95 \%$ confidence intervals. dagrass cultivars after inoculation with Ophiosphaerella spp. Plants were incubated for one month in the greenhouse and then at $4{ }^{\circ} \mathrm{C}$ for up to $45 \mathrm{~d}$ before freezing at $-4{ }^{\circ} \mathrm{C}$ for $1 \mathrm{~h}$. Vertical bars represent $95 \%$ confidence intervals.

was determined after 1 month as previously described. Acclimated and nonacclimated plants were analyzed separately as 4 (freezing regime) $\times 4$ (cultivar) $\times 5$ (pathogen $)$ factorial designs with 2 replications. The experiment was repeated and data from the two experiments were combined for analysis using SAS.

\section{Results}

Inoculum level and incubationduration. Doubling the inoculum level of $O$. herpotricha, but not $O$. korrae or $O$. narmari, decreased shoot

or the two $O$. korrae isolates, decreased with increased duration of incubation.

Cold acclimation and freezing. Disease severity in bermudagrass cultivars was affected by the interactions $(P<0.0001)$ of incubation and freezing temperatures following inoculation with Ophiosphaerella (Figs. 2 and 3). Shoot survival was $>60 \%$ in noninoculated cultivars incubated at $25^{\circ} \mathrm{C}$ before freezing at temperatures as low as $-8^{\circ} \mathrm{C}$, with the highest survival rates in Guymon and Tifgreen (Fig. 2). Shoot survival was further reduced by inoculation with some Ophiosphaerella, but generally only after plants were exposed to freezing temperatures less than $-4^{\circ} \mathrm{C}$. Aggressiveness of SDS pathogens varied with cultivar. $O$. korrae group I was the most aggressive on Tifgreen, whereas $O$. korrae group II was more damaging to Guymon.

Freezing temperature injury and SDS severity were more severe on all cultivars when they were incubated at $4{ }^{\circ} \mathrm{C}$ compared to $25^{\circ} \mathrm{C}$ before freezing. Shoot survival on noninoculated cultivars incubated at $4{ }^{\circ} \mathrm{C}$ decreased from $>95 \%$ after freezing at $-2{ }^{\circ} \mathrm{C}$ to $<25 \%$ following exposure to $-8^{\circ} \mathrm{C}$ (Fig. 3). Inoculations with SDS pathogens furtherreduced shoot survival, even at the highest freezing temperature. In general, O. herpotricha was more aggressive than either $O$. korrae I or II on 'Midlawn' and 'Tifgreen'.

\section{Discussion} incubation at $4{ }^{\circ} \mathrm{C}$ on individual cultivars (Fig. 1). Shoot survival in noninoculated Tifgreen and Midlawn was $>90 \%$ following cold acclimation for 15 and 30 d respectively, but dropped to $<60 \%$ on Midlawn at $45 \mathrm{~d}$. Generally, inoculations with Ophiosphaerella further reduced shoot survival on both cultivars. $O$. herpotricha caused the most disease severity, with almost no survival of Midlawn after $30 \mathrm{~d}$ of incubation at $4{ }^{\circ} \mathrm{C}$ and Tifgreen after $45 \mathrm{~d}$ at $4{ }^{\circ} \mathrm{C}$. Shoot survival on Tifgreen inoculated with $O$. herpotricha, but not with $O$. narmari
Increased resistance to spring dead spot has been noted in bermudagrass cultivars that also exhibited increased freezing resistance (Baird et al., 1998, Martin et al., 2001). We hypothesized that the less winter hardy cultivars 'Champion' and 'Tifgreen' would have more shoot mortality than Midlawn and Guymon. However inoculation with $O$. herpotricha, and in some cases with $O$. korrae, caused such extensive damage to cold-acclimated cultivars that differences
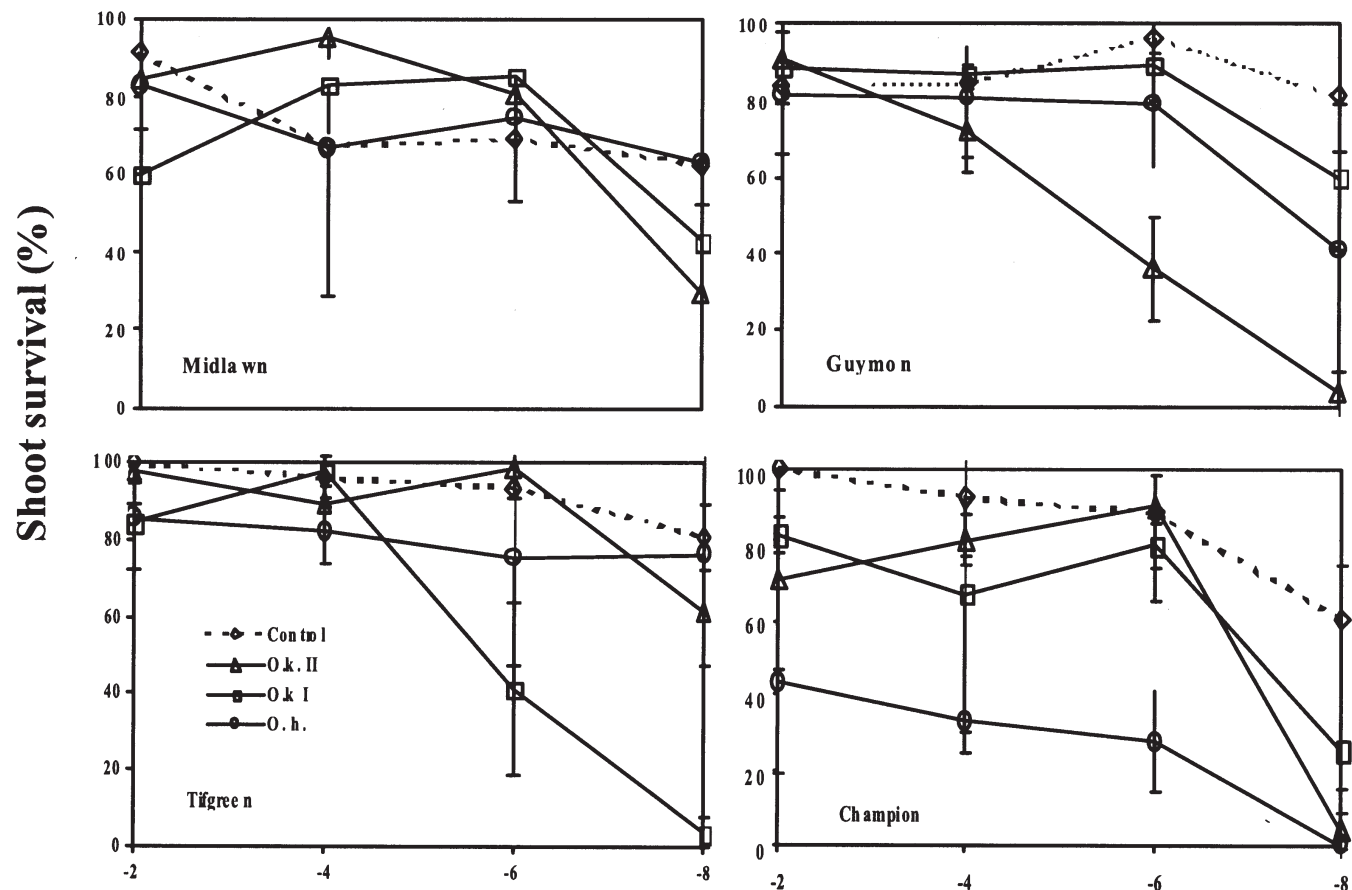

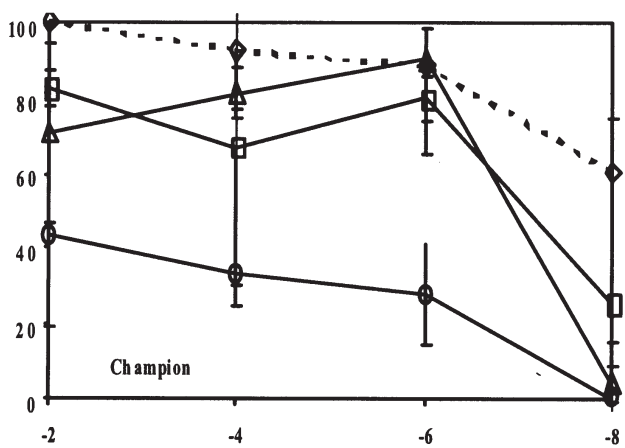

Temperature $\left({ }^{\circ} \mathrm{C}\right)$ 

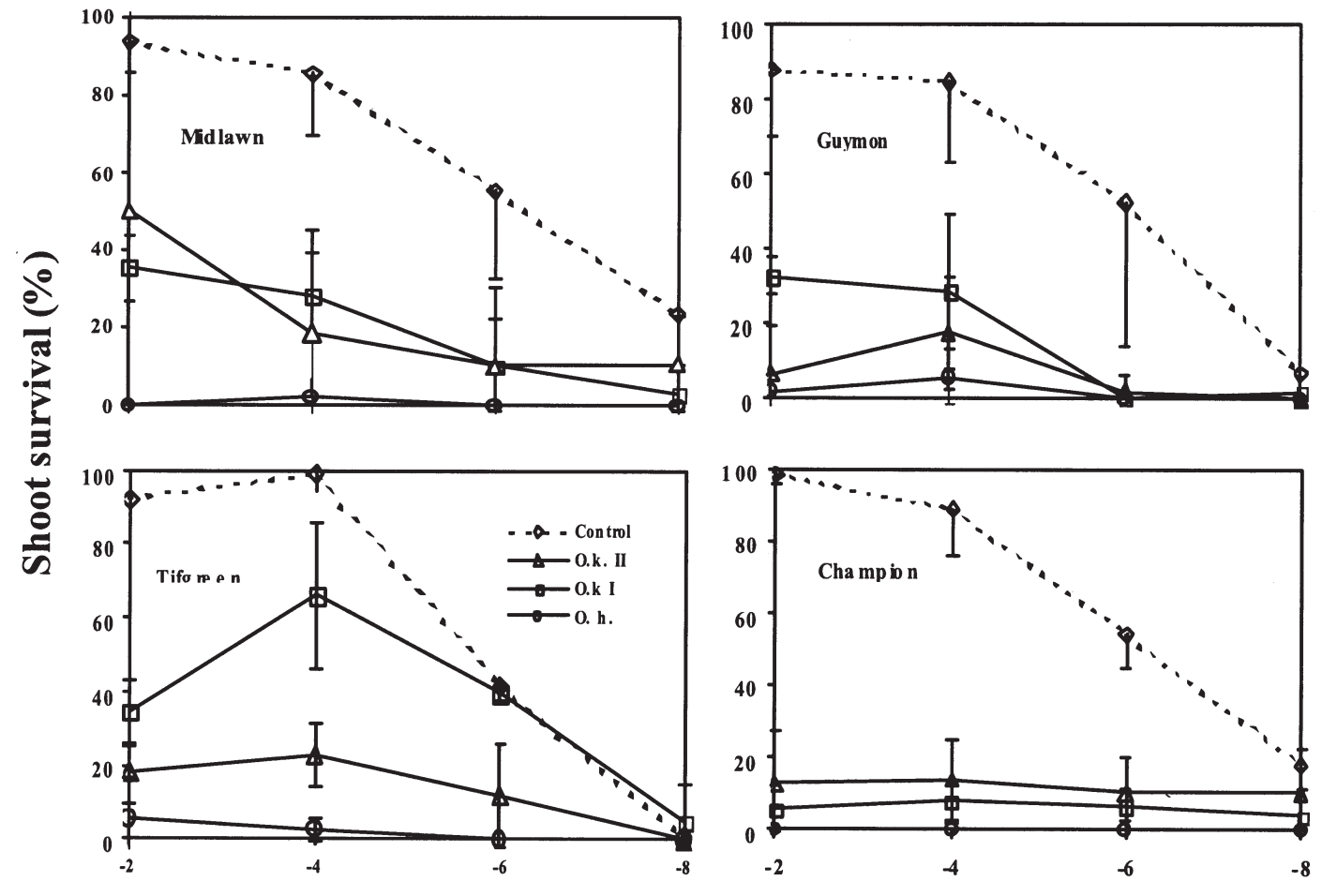

\section{Temperature $\left({ }^{\circ} \mathrm{C}\right)$}

were not discernable. Thus, our technique cannot currently be used to screen bermudagrass selections for SDS resistance. A more reliable technique may be to screen bermudagrass genotypes for SDS resistance in field trials after they have been tested for freeze tolerance under controlled conditions (Anderson and Taliaferro 2002; Anderson et al., 1993, 2003).

In the first experiment, inoculation with a single $O$. korrae isolate representing AFLP group I and II caused only a slight reduction in shoot survival when compared to noninoculated plants. Iriarte et al. (2004) reported differences in aggressiveness among $O$. korrae isolates to bermudagrass. In the second experiment we inoculated with a mixture of $O$. korrae isolates from each AFLP group to enhance disease development. This resulted in increased disease severity. We did not note any consistent differences in aggressiveness of isolates representing the two AFLP groups. These results are similar to those reported by Iriarte et al. (2004).

We initially incubated plants at $4{ }^{\circ} \mathrm{C}$ for 30 days to reduce detrimental effects of freezing nonacclimated bermudagrass (Nus and Shashikumar, 1993; Rajashekar, et al. 1983). However, SDS severity was greater in inoculated bermudagrass incubated at $4{ }^{\circ} \mathrm{C}$ compared to 25 ${ }^{\circ} \mathrm{C}$. Crahay et al. (1988) postulated that cool soil temperatures inhibit bermudagrass root growth while favoring root colonization by $O$. korrae. Smith (1971) observed that soil temperatures ranging from 10 to $20^{\circ} \mathrm{C}$ were most favorable for SDS development. Endo et al. (1985) reported severe damage to bermudagrass plants inoculated with $O$. korrae and incubated at 13 ${ }^{\circ} \mathrm{C}$, but only slight injury in plants maintained at $24{ }^{\circ} \mathrm{C}$. Conversely, Tisserat et al. (1989) found no differences in bermudagrass root discoloration caused by $O$. herpotrich a following incubation at 15 and $25^{\circ} \mathrm{C}$. Furthermore, in vitro growth of $O$. korrae and $O$. herpotricha was inhibited at temperatures below $10{ }^{\circ} \mathrm{C}$ (Tisserat et al., 1989, Crahay et al., 1988). Thus it is unlikely that the enhanced SDS severity we observed in cold-acclimated plants can be fully explained by increased root colonization by Ophiosphaerella spp. at $4{ }^{\circ} \mathrm{C}$. Alternatively cold acclimation may have further depleted carbohydrate reserves in crowns and roots that had already been colonized and damaged by SDS pathogens during incubation at $25^{\circ} \mathrm{C}$. Long exposures to low temperatures can deplete carbohydrate reserves in crown and roots and increase susceptibility to freeze damage (Dunn et al., 1980) and this may explain the decreased shoot survival in noninoculated, cold-acclimated plants we observed at freezing temperatures below $-4{ }^{\circ} \mathrm{C}$. We observed that 'Midlawn' had bermudagrass following exposure to freezing temperatures in the absence of disease. This was unexpected since previous studies have shown that 'Midlawn' is more freeze tolerant(Anderson et al., 2002). We noted that 'Tifgreen' grew more vigorously in the greenhouse and resulted in a more dense root system. This could have increased carbohydrate reserves and influence shoot survival following freezing. McCarty et al. (1991) found that carbohydrate reserves were lower in SDS-affected bermudagrass shoots following low temperature exposure in the fall, and that the diseased bermudagrass was more susceptible to freezing. Thus, SDS severity apparently is a function of reduced freeze tolerance caused by colonization and damage by SDS pathogens in late summer and fall at temperatures above $10^{\circ} \mathrm{C}$, and by carbohydrate depletion during winter.

\section{Literature cited}

Anderson, J.A., C.M. Taliaferro, and D.L. Martin. 1993.Evaluating freeze tolerance of bermudagrass in a controlled similar or lower survival rates than 'Tifgreen'
Fig. 3. Shoot survival in four bermudagrass cultivars after inoculation with $O$. herpotricha and $O$. korrae (isolates representing AFLP groups I and II). Plants were incubated in the greenhouse for one month and then in a growth chamber at $4^{\circ} \mathrm{C}$ for an additional month before freezing at either $-2,-4,-6$, or $-8{ }^{\circ} \mathrm{C}$. Vertical bars represent $95 \%$ confidence intervals.

environment. HortScience 28:955. Anderson, J.A., C.M. Taliaferro, and D.L. Martin. 2002. Freeze tolerance ofbermudagrasses: Vegetatively propagated cultivars intended for fairway and putting green use, and seed-propagated cultivars. Crop Sci. 42:975-977.

Anderson, J.A., C.M. Taliaferro, and D.L. Martin. 2003. Longer exposure durations increase freeze damage to turf bermudagrasses. Crop Sci. 45:973-977.

Baird, J.H., D.L. Martin, C.M. Taliaferro, M.E. Payton, and N.A. Tisserat. 1998. Bermudagrass resistance to spring dead spot caused by Ophiosphaerella herpotricha. Plant Dis. 82:771-774.

Crahay, J.N., P.H. Dernoeden, and N.R. O'Neill. 1988. Growth and pathogenicity of Leptosphaeria korrae in bermudagrass. Plant Dis. 72:945-949.

Dernoeden, P.H., J.H. Crahay, and D.B. Davis. 1991. Spring dead spot and bermudagrass quality as influenced by nitrogen source and potassium. Crop Sci. 31:1674-1680

Dunn J.H., C.J. Nelson, and J.L. Sebaugh 1980. Characterization of thatch, rhizomes, carbohydrates, and spring dead spot in twenty cultivars of bermudagrass. HortScience 105:653-657.

Endo, R.M., H.D. Ohr, and E.M. Krausman. 1985. Leptosphaeria korrae, a cause of the spring dead spot disease of bermudagrass in California. Plant Dis. 69:235-237.

Hawkes, N.J. 1987. Spring dead spot of Tifdwarf turf in South Australia. J. Sports Turf Res. Inst. 63:136-140.

Iriarte, F.B. 2003. Genetic diversity and aggressiveness of Ophiosphaerella korrae, one of the causal agents of spring dead spot disease of bermudagrass. PhD diss. Kan. State Univ., Manhattan.

Iriarte, F.B., H.C. Wetzel, III, J.D. Fry, D.L. Martin, and N.A. Tisserat. 2005. Genetic diversity and aggressiveness of Ophiosphaerella korrae, a cause of spring dead spot of bermudagrass. Plant Dis. 88:1341-1346.

Martin, D.L., G.E. Bell, J.H. Baird, C.M. Taliaferro, N.A. Tisserat, R.M. Kuzmic, D.D. Dobson, and J.A.Anderson. 2001a. Spring dead spot resistance and quality of seeded bermudagrasses under different mowing heights. Crop Sci. 41:451-456.

Martin, D.L., G.E. Bell, C.M. Taliaferro, N.A. Tisserat, J.H. Baird, D.D. Dobson, R.M. Kuzmic, and J.A. Anderson. 2001 b. Spring dead spotresistance of inter-specific hybrid bermudagrasses. J. Intl. Turf. Res. 9:3-6.

McCarty, L.B., J.M. Di Paola, and L.T. Lucas. 1991. Regrowth of bermudagrass infected with spring dead spot following low temperature exposure. Crop Sci. 31:182-184.

Nus, J.L. and K. Shashikumar. 1993. Fungi associated with spring dead spot reduces freezing resistance in bermudagrass. HortScience 28:306-307.

Pair, J.C., F.J. Crowe, and W.G Willis. 1986. Transmission of spring dead spot disease of bermudagrass by turf/soil cores. Plant Dis. 70:877-887.

Rajashekar, C.B., D. Tao, and P.H. Li. 1983. Freezing resistance and cold acclimation in turfgrasses. HortScience 18:91-93.

Smith,A.M. 1971. Spring dead spot of couch grass turf in New South Wales. J. Sports Turf Res. Inst. 47:54-59.

Tisserat, N. and J. Fry. 1997. Cultural practices to reduce spring dead spot (Ophiosphaerella herpotricha) severity in Cynodon datylon. J. Intl. Turf. Res. 8:931-936.

Tisserat, N.A., J.C. Pair, and A. Nus. 1989. Ophiosphaerella herpotricha, a cause of spring dead spot of bermudagrass in Kansas. Plant Dis. 73:933-937

Wetzel, III, H.C., D.Z.Skinner, and N.A. Tisserat. 1999. Geographic distribution and genetic diversity of three Ophiosphaerella species that cause spring dead spot of bermudagrass. Plant Dis. 83:1160-1166. 